\title{
RESEARCH
}

Open Access

\section{Termination of pregnancy data completeness and feasibility in population- based surveys: EN-INDEPTH study}

Yeetey Akpe Kwesi Enuameh ${ }^{1,2^{*}}$, Francis Dzabeng ${ }^{1}$, Hannah Blencowe ${ }^{3}$, Sanne M. Thysen ${ }^{4,5,6}$, Solomon Mekonnen Abebe ${ }^{7,8}$, Kwaku Poku Asante', Charlotte Tawiah', Vladimir Sergeevich Gordeev" ${ }^{3,9}$, Wisdom Adeapena', Doris Kwesiga ${ }^{10,11,12}$, Simon Kasasa ${ }^{13,14,15}$, Charles Zandoh¹, Md. Ali Imam6, Seeba Amenga-Etego 1, Sam K. Newton 1,17, Seth Owusu-Agyei 1,18, Joy E. Lawn³, Peter Waiswa 10,19,20†, Jenny A. Cresswell ${ }^{3+}$ and the Every Newborn-INDEPTH Study Collaborative Group

\begin{abstract}
Background: Termination of pregnancy (TOP) is a common cause of maternal morbidity and mortality in low- and middle-income countries. Population-based surveys are the major data source for TOP data in LMICs but are known to have shortcomings that require improving. The EN-INDEPTH multi-country survey employed a full pregnancy history approach with roster and new questions on TOP and Menstrual Restoration. This mixed methods paper assesses the completeness of responses to questions eliciting TOP information from respondents and reports on practices, barriers, and facilitators to TOP reporting.

Methods: The EN-INDEPTH study was a population-based cross-sectional study. The Full Pregnancy History arm of the study surveyed 34,371 women of reproductive age between 2017 and 2018 in five Health and Demographic Surveillance System (HDSS) sites of the INDEPTH network: Bandim, Guinea-Bissau; Dabat, Ethiopia; IgangaMayuge, Uganda; Kintampo, Ghana; and Matlab, Bangladesh. Completeness and time spent in answering TOP questions were evaluated using simple tabulations and summary statistics. Exact binomial $95 \%$ confidence intervals were computed for TOP rates and ratios. Twenty-eight (28) focus group discussions were undertaken and analysed thematically.

\footnotetext{
* Correspondence: yeetey@gmail.com

${ }^{\dagger}$ Peter Waiswa and Jenny A. Cresswell are joint senior authors.

${ }^{1}$ Kintampo Health Research Centre, Kintampo, Ghana

${ }^{2}$ Dept of Epidemiology \& Biostatistics, Kwame Nkrumah University of Science

\& Technology, Kumasi, Ghana

Full list of author information is available at the end of the article
}

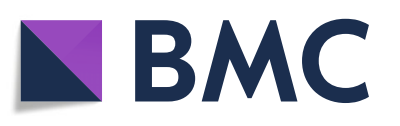

(c) The Author(s). 2021 Open Access This article is licensed under a Creative Commons Attribution 4.0 International License, which permits use, sharing, adaptation, distribution and reproduction in any medium or format, as long as you give appropriate credit to the original author(s) and the source, provide a link to the Creative Commons licence, and indicate if changes were made. The images or other third party material in this article are included in the article's Creative Commons licence, unless indicated otherwise in a credit line to the material. If material is not included in the article's Creative Commons licence and your intended use is not permitted by statutory regulation or exceeds the permitted use, you will need to obtain permission directly from the copyright holder. To view a copy of this licence, visit http://creativecommons.org/licenses/by/4.0/ The Creative Commons Public Domain Dedication waiver (http://creativecommons.org/publicdomain/zero/1.0/) applies to the data made available in this article, unless otherwise stated in a credit line to the data. 
(Continued from previous page)

Results: Completeness of responses regarding TOP was between 90.3 and $100.0 \%$ for all question types. The new questions elicited between 2.0\% (1.0-3.4), 15.5\% (13.9-17.3), and 11.5\% (8.8-14.7) lifetime TOP cases over the roster questions from Dabat, Ethiopia; Matlab, Bangladesh; and Kintampo, Ghana, respectively. The median response time on the roster TOP questions was below 1.3 minutes in all sites. Qualitative results revealed that TOP was frequently stigmatised and perceived as immoral, inhumane, and shameful. Hence, it was kept secret rendering it difficult and uncomfortable to report. Miscarriages were perceived to be natural, being easier to report than TOP. Interviewer techniques, which were perceived to facilitate TOP disclosure, included cultural competence, knowledge of contextually appropriate terms for TOP, adaptation to interviewee's individual circumstances, being non-judgmental, speaking a common language, and providing detailed informed consent.

Conclusions: Survey roster questions may under-represent true TOP rates, since the new questions elicited responses from women who had not disclosed TOP in the roster questions. Further research is recommended particularly into standardised training and approaches to improving interview context and techniques to facilitate TOP reporting in surveys.

Keywords: Population-based surveys, Household survey, Completeness, Termination of pregnancy, Abortion, Health and demographic surveillance

\section{Key findings}

\section{WHAT IS NEW?}

- What was known already: Termination of pregnancy (TOP), especially if unsafe, remains a significant cause of maternal death, especially in low-and middle-income countries. Population-based surveys are key, yet are known to under-capture TOP.

- What was done: The EN-INDEPTH multi-country survey included a full pregnancy history by roster and new questions on TOP and Menstrual Restoration. Data on 34,371 women were analysed to assess the completeness of responses to roster and new questions to elicit TOP information. Perceptions, practices, barriers, and facilitators to TOP reporting were studied.

\section{What was found in the quantitative data?}

- Completeness of responses: Was high for roster, new TOP questions, and Menstrual Restoration questions and ranged between 90.3 and $100 \%$. The median response time on the roster TOP questions was below 1.3 minutes in all sites.

- Data utility: When the new TOP questions were used, between 2.0 and $15.5 \%$ of women who had not disclosed TOP in the roster questions reported TOP. The highest proportion of women who reported TOP in the Roster (14.0 \%) and new TOP questions (15.5\%) were from Matlab, Bangladesh. IgangaMayuge, Uganda, had the highest proportion who reported having used Menstrual Restoration (17.2\%). Termination of pregnancy rates for the 5 years preceding the EN-INDEPTH survey generated from the Full Pregnancy History roster questions ranged between 0.3 (Dabat, Ethiopia) to 19.3 (Kintampo, Ghana) TOPs per 1000 women aged 15-49 years.

\section{What was found in the qualitative data?}

\section{- Barriers/enablers to reporting}

- Termination of pregnancy was perceived as difficult and uncomfortable to disclose by many respondents. This was due to its perceived immoral, inhumane, or shameful nature that made it a secret to be kept by women. Miscarriages felt natural so were perceived as easier to disclose than TOP by women.

- Good interviewer techniques including cultural competence, knowledge of contextually appropriate expressions of TOP, adaptation to interviewee's individual circumstances, being non-judgmental, speaking a common language, and providing detailed informed consent were perceived by interviewers and women to facilitate TOP disclosure.

What next in measurement and research?

- Measurement improvement now: Interviewers for future

\section{Key findings (Continued)}

population-based surveys should be selected and given standardised training with enhanced appreciation of interview techniques specifically to address stigma and contextual factors to facilitate TOP reporting. Improving survey processes, including use of nonjudgemental language in translations of questions and prompts, is necessary.

- Research needed: Further adequately powered experimental studies are needed to validate the use of new TOP questions in eliciting information on TOP to improve monitoring of this outcome in surveys.

\section{Background}

Accurate termination of pregnancy (TOP) rates are difficult to obtain, particularly in low- and middle-income countries (LMICs) with restrictive laws, or where incomplete coverage of routine data collection systems requires reliance on household surveys where under-reporting is common. Globally, some reduction has been seen in TOP rates from an estimated 40 per 1000 females aged 15-49 years in 1990-1994, to 35 per 1000 in 2010-2014 [1, 2]. However, whilst TOP rates have declined significantly in high-income countries (HICs), they have remained roughly constant in LMICs [1]. Current rates are 36 and 27 per 1000 for LMICs and HICs, respectively [1]. Unsafe TOPs are significantly higher in LMICs with highly restrictive TOP laws compared to HICs with less restrictive laws [3-5]. Up to 55.7 million TOPs occurred each year between 2010 and 2014 worldwide, of which 25.1 million (45.1\%) were unsafe; LMICs contributed 24.3 million (97\%) of these [4]. Unsafe TOPs contribute significantly to maternal morbidity and mortality $[3,5,6]$. However, underreporting of TOP remains a universal concern as evidenced in some countries with relatively liberal laws in which between 20 and $60 \%$ of cases were not disclosed during surveys [7-10].

Data regarding TOP in LMICs is predominantly generated from health facility data and household surveys, notably 
Demographic and Health Surveys (DHS), plus special Maternal Health Surveys [11]. Other studies have employed different methods to collect information on TOP such as the confidante method, the list experiment, the abortion incidence method (AICM), and the modified AICM [12-14].

DHS surveys have, until now, generally employed standard questionnaires with a Full Birth History approach (FBH) to collect information on pregnancy losses, not distinguishing between induced (TOP) and spontaneous abortions (miscarriages) [15-17]. The Full Pregnancy History (FPH), however, elicits details of all pregnancy outcomes, facilitating distinctions between TOP and miscarriages [15]. Termination of pregnancy data collected via face-to-face DHS have known limitations including misreporting and underreporting, which may be due to recall bias or provision of socially desirable responses, amongst others $[18,19]$. Previous studies have found that interviewers may influence TOP reporting outcomes [20] and perceived stigma led to misreporting of TOP as miscarriages in surveys in some communities [21].

Termination of pregnancy rates are known to be related to fertility levels of populations and access to TOP. The total fertility rates for the sites included in the EN-INDE PTH study were Matlab, Bangladesh-2.6; Dabat, Ethiopia-3.8; Kintampo, Ghana-4.1; IgangaMayuge, Uganda-4.3; and Bandim, Guinea-Bissau-4.2 (urban) and 5.1 (rural) [15]. All countries involved in this study are considered as having restrictive TOP laws $[3,22,23]$. Previously reported TOP rates for Bangladesh [24, 25], Ethiopia [26], Ghana [12], and Uganda [27] were 29, 28, 44, and 39 per 1000 women aged $15-49$ years, respectively. No studies were found reporting TOP rates in Guinea-Bissau.

Few studies have assessed the performance of survey questions by virtue of their completeness of responses in the capture of TOP data in LMICs. Sedgh et al. observed the challenge in generating valid and reliable abortion statistics, recommending additional research to improve monitoring of trends [2]. The extent to which study participants fully respond to key questions related to TOP is referred to as "data completeness" in the context of this manuscript.

This paper is part of a series of papers from the Every Newborn-International Network for the Demographic Evaluation of Populations and their Health (EN-INDEPTH) study in five Health and Demographic Surveillance System (HDSS) sites in Africa and Asia, to improve the measurement of pregnancy outcomes in population-based household surveys. This paper addresses the following objectives:

1) Quantitative analysis of performance of TOP survey questions: To evaluate modified and new questions' influence on TOP reporting by women in a population-based survey, including completeness, time spent responding to questions, and plausibility of reported TOP rates.

\section{2) Qualitative assessment regarding TOP reporting:}

To describe community perceptions, practices, barriers, and facilitators to reporting TOP from the perspective of interviewers and mothers, and how these influenced TOP capture in the EN-INDEPTH survey.

\section{Methods}

\section{Study design and setting}

The EN-INDEPTH study was a population-based crosssectional study undertaken between July 2017 and August 2018. Five HDSS sites belonging to the INDEPTH Network were involved in the study. The sites are located in Dabat, Ethiopia; Bandim, Guinea-Bissau; IgangaMayuge, Uganda; Kintampo, Ghana; and Matlab, Bangladesh. The study's primary objective was to compare two methods of retrospective recording of pregnancy outcomes used in the DHS, i.e. a Full Birth History with additional questions on pregnancy losses $(\mathrm{FBH}+)$, as per the DHS7 standard and the 2016 Nepal DHS Full Pregnancy History (FPH). Whilst some sites were familiar with $\mathrm{FBH}+$, no sites had previous experience of FPH. To contribute to the understanding of the measurement of TOP in population-based surveys, focus group discussions (FGDs) with women survey respondents and interviewers (Additional file 1) were performed between February and August 2018 [28]. Information on perceptions, practices, barriers, and facilitators to reporting TOP and understanding its measurement was collected.

\section{Study population and sample}

Women aged 15-49 years totalling 69,176 participated in the EN-INDEPTH survey. Survey questions on FBH+ and $\mathrm{FPH}$ were administered to 34,805 and 34,371 women, respectively, and data were collected on Android tablets using Survey Solutions software [29]. The study protocol provides details on site selection, sampling processes for the modules, and other related information [15]. Findings of the primary objectives of the study have been published elsewhere [28, 30].

\section{Participant selection and training}

The quantitative arm of the study had women participants from the five HDSS sites being randomly assigned individually to either the $\mathrm{FBH}+$ or the FPH [15, 30]. Women participants of the EN-INDEPTH survey and interviewers who conducted the survey were purposively sampled for the qualitative arm of the study [ 15 , 28]. Contextual factors such as religion and availability of skilled personnel amongst others could have influenced the choice of interviewers for the survey.

Training of the data collectors for both the qualitative and quantitative aspects of this study was based on manuals adapted from the standard DHS interviewer manual [28] and those of the World Bank Survey Solution 
manuals [15]. The training was broad in nature covering all questions related to the survey and focused group discussions.

\section{EN-INDEPTH survey questions on TOP in the FPH questionnaire}

All women in the FPH arm of the EN-INDEPTH study provided information on all pregnancies in their lifetime regardless of the outcome. Menstrual Restoration questions and additional new TOP questions sought to further explore pregnancy outcomes that were not reported by the women in the roster section. Four sets of questions related to TOP were used: (i) standard TOP questions from the FPH roster were used to generate TOP rates/ratios for all five HDSS sites in the 5 years preceding the survey (Additional files 2 and 3); (ii) a single roster question assessed whether pregnancies earlier reported as "born dead" or "lost before term" were spontaneous or induced losses for all five HDSS sites (Additional file 4); (iii) new questions on Menstrual Restoration elicited information on measures respondents employed for resumption of missed periods for Dabat, Ethiopia; IgangaMayuge, Uganda; and Kintampo, Ghana; (iv) new questions on TOP probed respondents on the standard TOP questions who hitherto did not report TOP in Dabat, Ethiopia; Kintampo, Ghana; and Matlab, Bangladesh. These questions enquired of any unwanted pregnancies that ended up in non-live pregnancy outcomes (Additional file 4).

\section{Data analysis}

\section{Objective 1: Quantitative analysis of performance of TOP survey questions}

We computed point estimates and exact binomial 95\% confidence intervals for TOP rates and ratios (Additional files 2 and 3). Completeness of responses was assessed for the FPH roster questions, and new questions on Menstrual Restoration and TOP in percentages-as number of responses to a question (numerator) per all eligible responses (denominator) to that question. "Yes" and "No" were the response options to the completeness questions, "Don't know" was not an option (Additional file 4). The essence of this analysis was to explore how feasible it is for women from sites with restrictive TOP laws to respond to such sensitive questions.

Paradata gathered by the Survey Solutions software [29] provided information on time spent responding to questions in all three sets of TOP questions. The mean and median times taken to answer all TOP questions were assessed at each of the five HDSS sites. Descriptive analyses were done to compare women's response time to TOP questions by HDSS sites. To account for the variation in number of TOP questions asked to women by HDSS, we standardised the time taken by the total number of TOP questions asked by each HDSS site. During analysis, the time was truncated to
0.5-30 min to eliminate outliers due to interruptions of interviews. Shorter response times documented by paradata were to signify less time spent on questions and by inference less time burden on respondents. Longer times could however imply respondents struggling with understanding of questions or interviewers having issues with their administration [31]. Stata version 15.1 was used for quantitative data management and analyses [32].

Results are reported in accordance with STROBE Statement checklist for cross-sectional studies [22] (Additional file 5).

\section{Objective 2: Qualitative assessment regarding TOP reporting}

Thematic analysis was conducted using an iterative process guided by an a priori codebook and addition of new codes that emerged during analysis [28]. Themes were summarised and grouped to explore how findings influence the measurement of TOP in population-based surveys. Qualitative data were transcribed using a combination of notes and audio recordings that were coded and analysed using NViVo version 12 [33].

\section{Results}

Information on TOP was collected from a sample of 34, 371 women of reproductive age who participated in the FPH arm of the EN-INDEPTH survey (Fig. 1).

For the quantitative arm of the study, age distribution varied by site and ranged between 15 and 49 years. Respondents with no education were mostly in Dabat, Ethiopia, and Kintampo, Ghana, and those with higher levels were in IgangaMayuge, Uganda, and Matlab, Bangladesh, with Bandim, Guinea-Bissau being mid-way between the two groups. Majority in IgangaMayuge, Uganda, and Matlab, Bangladesh, were Muslim with Christianity dominating in the other three sites. Parity was predominantly three and below except for Kintampo, Ghana (Table 1).

For the qualitative arm of the study, two-thirds of women and a third of interviewers were aged between 25 and 34 years. Female interviewers were the majority in Bandim, Guinea Bissau; Dabat, Ethiopia; and Matlab, Bangladesh, the minority in Kintampo, Ghana, and evenly split in IgangaMayuge, Uganda (Additional file 6).

Quantitative analysis of performance of TOP survey questions Completeness of responses to the roster TOP question was 99.7\% (Table 2). Lifetime TOP rates generated from the roster TOP questions were as follows: $13.2 \%$ (11.4-15.2) (Kintampo, Ghana), 14.0\% (9.0-15.7) (Matlab, Bangladesh), 6.8\% (5.5-8.2) (Bandim, Guinea-Bissau), 6.0\% (4.8-7.5) (IgangaMayuge, Uganda), and $1.2 \%$ (0.3-2.9) (Dabat, Ethiopia) (Table 3). Furthermore, 5-year TOP ratios prior to the EN-INDEPTH survey for all sites ranged from 0.4 $(0.0-1.4)$ to $12.5(10.3-14.9)$ per 1000 livebirths 


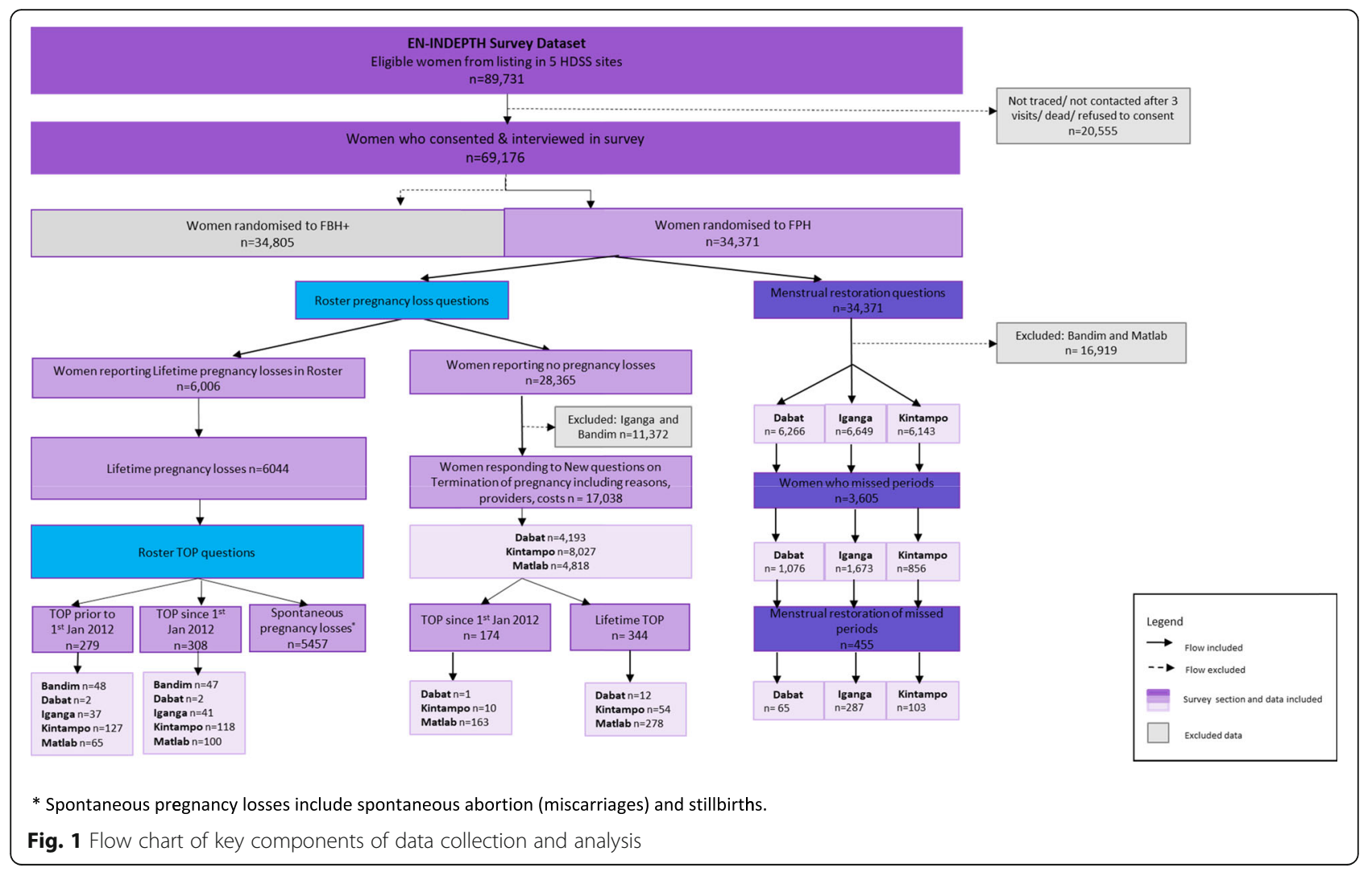

(Additional file 3) and TOP rates from $0.3(0.0-1.2)$ to 19.2 (15.9-22.13) per 1000 women aged 15-49years (Additional file 2).

Completeness of responses to questions was high: on menstrual restoration (i.e. having done something to restore missed periods) - $100.0 \%$; on methods employed100.0\%; and place where it was restored-90.3\% (Table 2). The lifetime percentage of women who reported having their menstruation periods restored was 17.2\% (15.4-19.0) (IgangaMayuge, Uganda), 12.0\% (9.9-14.4) (Kintampo, Ghana), and 6.0\% (4.7-7.6) (Dabat, Ethiopia) (Table 3).

Completeness of responses was $99.8 \%$ to the question on actions being successfully taken to end unwanted pregnancies, and $100.0 \%$ for questions on steps taken to terminate unwanted pregnancies, terminations that occurred in the past 5 years, main reasons for the termination, how the termination was done, person who suggested the termination, who performed the termination, where the termination was done and the cost of the termination process (Table 2). The new questions on TOP elicited an extra 2.0\% (1.0-3.4), 15.5\% (13.9$17.3)$, and $11.5 \%(8.8-14.7)$ lifetime TOP cases over the roster TOP questions from Dabat, Ethiopia; Matlab, Bangladesh; and Kintampo, Ghana, respectively (Table 3 and Additional file 7). Furthermore, 8.3\% (0.2-38.5), $58.6 \%(52.6-64.5)$, and $18.5 \%(9.3-31.4)$ of the lifetime
TOPs in Dabat, Ethiopia; Matlab, Bangladesh; and Kintampo Ghana, respectively, occurred in the last 5 years prior to the EN-INDEPTH survey (Additional file 7). It should be emphasised that these respondents had hitherto not reported having had a TOP from the roster TOP questions.

The median response time on the roster TOP questions was below 1.3 minutes in all sites. Mean times of responses to roster questions was relatively low in Dabat $(1.1 \pm 0.8 \mathrm{~min})$ and high in Matlab $(3.7 \pm 4.7 \mathrm{~min})$ (Fig. 2 and Additional file 8). The mean response time of women to new questions on TOP in Dabat, Ethiopia, was lower $(1.5 \pm 1.9)$ than that of Matlab, Bangladesh, $(5.0 \pm 4.8)$ and Kintampo, Ghana $(2.5 \pm 2.2)$. In addition, women in three HDSS sites (Dabat, IgangaMayuge, and Kintampo) spent less than 2 min on average in responding to the menstrual restoration questions (Fig. 2 and Additional file 8).

\section{Qualitative assessment regarding TOP reporting}

Findings from the qualitative arm of the study are presented under the themes perceptions, practices, barriers, and facilitators to reporting of TOP (Table 4).

\section{Community perceptions and practices on reporting of TOP}

There was a perception reported amongst both women and interviewers from most sites that TOP was immoral 
Table 1 Socio-demographic characteristics of EN-INDEPTH survey FPH group respondents

\begin{tabular}{|c|c|c|c|c|c|c|}
\hline \multicolumn{7}{|c|}{ Health and demographic surveillance system sites } \\
\hline & $\begin{array}{l}\text { Bandim, Guinea- } \\
\text { Bissau }(N=4660)\end{array}$ & $\begin{array}{l}\text { Dabat, Ethiopia } \\
(N=6266)\end{array}$ & $\begin{array}{l}\text { IgangaMayuge, } \\
\text { Uganda }(N=6649)\end{array}$ & $\begin{array}{l}\text { Matlab, Bangladesh } \\
(N=10,653)\end{array}$ & $\begin{array}{l}\text { Kintampo, Ghana } \\
(N=6143)\end{array}$ & $\begin{array}{l}\text { Total }(N=34, \\
371)\end{array}$ \\
\hline & $n(\%)$ & $n(\%)$ & $n(\%)$ & $n(\%)$ & $n(\%)$ & $n(\%)$ \\
\hline \multicolumn{7}{|l|}{ Age } \\
\hline $15-19$ & $220(4.7)$ & $1337(21.3)$ & $1912(28.8)$ & $547(5.1)$ & $149(2.4)$ & $4165(12.1)$ \\
\hline $20-24$ & $1037(22.3)$ & $961(15.3)$ & $1319(19.8)$ & $2722(25.6)$ & $903(14.7)$ & $6942(20.2)$ \\
\hline $25-29$ & $1207(25.9)$ & $1053(16.8)$ & $896(13.5)$ & $3067(28.8)$ & $1285(20.9)$ & $7508(21.8)$ \\
\hline $30-34$ & $1072(23.0)$ & $857(13.7)$ & $686(10.3)$ & $2554(24)$ & $1499(24.4)$ & $6668(19.4)$ \\
\hline $35+$ & $1116(23.9)$ & $2058(32.8)$ & $1831(27.5)$ & $1763(16.5)$ & $2301(37.5)$ & 9069 (26.4) \\
\hline Missing & $8(0.2)$ & $0(0.0)$ & $5(0.1)$ & $0(0.0)$ & $6(0.1)$ & $19(0.1)$ \\
\hline \multicolumn{7}{|l|}{ Education level } \\
\hline No education & $1291(27.7)$ & 3047 (48.6) & $444(6.7)$ & $487(4.6)$ & 2418 (39.4) & 7687 (22.4) \\
\hline Primary only & $1366(29.3)$ & $1688(26.9)$ & 3018 (45.4) & 2017 (18.9) & $2754(44.8)$ & $10,843(31.5)$ \\
\hline Primary and secondary & $1656(35.5)$ & $877(14)$ & $2763(41.6)$ & $6690(62.8)$ & $892(14.5)$ & $12,878(37.5)$ \\
\hline Higher & $340(7.3)$ & $654(10.4)$ & $420(6.3)$ & $1457(13.7)$ & $75(1.20)$ & $2946(8.6)$ \\
\hline Missing & $7(0.2)$ & $0(0.0)$ & $4(0.1)$ & $2(0.0)$ & $4(0.1)$ & $17(0.1)$ \\
\hline \multicolumn{7}{|l|}{ Religion } \\
\hline Christian & $1907(41)$ & 6009 (95.9) & 3039 (45.8) & $0(0.0)$ & $3875(63.1)$ & $14,830(43.2)$ \\
\hline Muslim & $1834(39.4)$ & $257(4.1)$ & $3592(54.1)$ & $9430(88.5)$ & 1889 (30.8) & $17,002(49.5)$ \\
\hline Other or none & $908(19.5)$ & $0(0)$ & $11(0.2)$ & $1221(11.5)$ & $374(6.1)$ & $2514(7.3)$ \\
\hline \multicolumn{7}{|l|}{ Parity } \\
\hline 3 or less births & 3099 (66.5) & $3815(60.9)$ & $4208(63.3)$ & $9361(87.9)$ & $3073(50.0)$ & $23,556(68.5)$ \\
\hline$>3$ births & $1561(33.5)$ & $2451(39.1)$ & $2441(36.7)$ & $1292(12.1)$ & $3070(50.0)$ & $10,815(31.5)$ \\
\hline \multicolumn{7}{|l|}{ Socioeconomic status } \\
\hline Poorest & $938(20.1)$ & $1427(22.8)$ & $1321(19.9)$ & $2175(20.4)$ & $1226(20.0)$ & 7087 (20.6) \\
\hline 2 & $893(19.2)$ & $1074(17.1)$ & $1319(19.8)$ & $2074(19.5)$ & $1248(20.3)$ & $6608(19.2)$ \\
\hline 3 & $964(20.7)$ & $1244(19.9)$ & $1342(20.2)$ & $2125(19.9)$ & $1273(20.7)$ & $6948(20.2)$ \\
\hline 4 & $969(20.8)$ & $1255(20.0)$ & $1358(20.4)$ & $2133(20.0)$ & $1211(19.7)$ & $6926(20.2)$ \\
\hline Richest & $896(19.2)$ & $1266(20.2)$ & $1309(19.7)$ & $2146(20.1)$ & 1185 (19.3) & $6802(19.8)$ \\
\hline
\end{tabular}

and inhuman as per cultural and religious values, resulting in a perceived difficulty in reporting these events. Persons who had undertaken TOP were perceived to have taken a life.

Why did you abort the baby? Why did you kill a life? (Woman, IgangaMayuge, Uganda)

Perceived shame associated with TOP was mentioned by women and interviewers as contributing to TOPs being kept secret, and hence rarely reported, especially in young females.

It is shameful to tell people that you have aborted a pregnancy, so it is not possible to easily disclose it (Woman, Kintampo, Ghana)
Women observed that grieving openly for a TOP was virtually non-existent as such pain was considered selfinflicted. Interviewers noted that livebirths were easier to report than TOP and some reported them as miscarriages instead.

\section{Perceived barriers to reporting TOP}

Interviewers felt unable to ask questions on TOP apprehensive of legal, traditional, and religious implications-women also confirmed this notion. According to interviewers, they were perceived at times as disrespectful when they attempted probing women about TOP. Interviewers and women observed that stigmatisation of TOP was very commonly reported in three out the five sites, to the extent that those who had engaged in it were, in many cases, referred to as murderers. 
Table 2 Completeness of responses to questions regarding termination of pregnancy in the EN-INDEPTH survey

\begin{tabular}{|c|c|c|c|c|c|}
\hline Index question & $\begin{array}{l}\text { No. of responses } \\
\text { made }\end{array}$ & Base question & $\begin{array}{l}\text { No. of expected } \\
\text { responses }\end{array}$ & $\begin{array}{l}\text { Completeness } \\
\text { of responses } \\
(\%)\end{array}$ & Comments \\
\hline \multicolumn{6}{|c|}{$\begin{array}{l}\text { a. Roster TOP questions (Bandim, Dabat, Iganga-Mayuge, Kintampo, Matlab)_Directly eliciting information as to whether pregnancies of babies } \\
\text { born dead or lost before birth had been tampered with }\end{array}$} \\
\hline $\begin{array}{l}\text { Did you or someone else } \\
\text { do something to end this } \\
\text { pregnancy? (yes/no) }\end{array}$ & 6044 & $\begin{array}{l}\text { RQ1: Was the "rostertitle" born } \\
\text { alive, born dead, or lost before } \\
\text { birth? (alive/dead/lost before } \\
\text { term) }\end{array}$ & 6064 & $\begin{array}{l}6044 / 6064= \\
(99.7 \%)\end{array}$ & $\begin{array}{l}\text { The base question } \\
\text { focused on those born } \\
\text { "dead or lost before } \\
\text { term" }\end{array}$ \\
\hline
\end{tabular}

b. New Menstrual Restoration questions (Dabat, Iganga-Mayuge, and Kintampo)_Eliciting information as to whether those who had missed their period did something for it to resume, how and where that was done

\begin{tabular}{|c|c|c|c|c|c|}
\hline $\begin{array}{l}\text { Did you do anything to } \\
\text { resume your period? } \\
\text { (yes/no) }\end{array}$ & 3605 & $\begin{array}{l}\text { AQ1: Have you ever had a } \\
\text { period that was more than } \\
\text { one week late? (yes/no) }\end{array}$ & 3605 & $\begin{array}{l}3605 / 3605= \\
100.0 \%\end{array}$ & $\begin{array}{l}\text { Those with "yes" } \\
\text { responses in the base } \\
\text { question, answered the } \\
\text { index questions over } \\
\text { the next three } \\
\text { questions. }\end{array}$ \\
\hline $\begin{array}{l}\text { What did you do to resume } \\
\text { your period? (pill/ } \\
\text { injectables/herb/other) }\end{array}$ & 455 & $\begin{array}{l}\text { AQ2: Did you do anything to } \\
\text { resume your period? (yes/no) }\end{array}$ & 455 & $\begin{array}{l}455 / 455= \\
100.0 \%\end{array}$ & \\
\hline $\begin{array}{l}\text { Where did you go to get } \\
\text { help to get your period }\end{array}$ & 411 & $\begin{array}{l}\text { AQ2: Did you do anything to } \\
\text { resume your period? (yes/no) }\end{array}$ & 455 & $\begin{array}{l}411 / 455= \\
90.3 \%\end{array}$ & \\
\hline
\end{tabular}
get your period back? (venue)

resume your period? (yes/no)

c. NEW TOP questions (Dabat, Kintampo, and Matlab)_focused on those who did not report a TOP at the roster level, asking them of unwanted pregnancies that did not result in birth of a live child. It then further probes the outcome of the non-live birth.

\begin{abstract}
It is not uncommon for a woman to get pregnant at a time when circumstance would make it difficult to have a child. Have you ever gotten pregnant at a time when it would have been difficult for you to have a child, or when you did not want to have one? (yes/no)
\end{abstract}

Did you or anyone else ever successfully do anything to end that pregnancy? (yes/no) [abortion over lifetime]

Did you have such a pregnancy in the last 5 years? (yes/no)

What was the MAIN reason 174 you decided to have this (last) abortion?

What did you do to end this pregnancy?

Who suggested that you might have an abortion?

Who did you see to get this done?
17038
NQ1: Women sometimes have pregnancies that do not result in a live born child. That is, a pregnancy can end in a miscarriage, abortion or the child can be born dead. Have you ever had a pregnancy that did not end in a livebirth? (yes/no

NQ2: It is not uncommon for a woman to get pregnant at a time when circumstance would make it difficult to have a child. Have you ever gotten pregnant at a time when it would have been difficult for you to have a child, or when you did not want to have one? (yes/no)

NQ3: Did you or anyone else ever successfully do anything to end that pregnancy? (yes/no) [abortion over lifetime]

NQ4: Did you have such a pregnancy in the last 5 years? (yes/No)

NQ4: Did you have such a pregnancy in the last 5 years? (yes/no)

NQ4: Did you have such a pregnancy in the last 5 years? (yes/no)

NQ4: Did you have such a pregnancy in the last 5 years? (yes/no)
17,071

$17,038 / 17,071$ $=99.8 \%$

Those who answered "no" to the base question are those who responded to the index question

2870

$2870 / 2870=$

Those who responded "yes" to the base questions were those responding to the index question.

$344 / 344=$ $100.0 \%$

Response is count of pregnancies

$174 / 174=$ $100.0 \%$

Response is count of reasons

$174 / 174=$ $100.0 \%$

Response is count of action taken

Response is count of persons who made the suggestion 
Table 2 Completeness of responses to questions regarding termination of pregnancy in the EN-INDEPTH survey (Continued)

\begin{tabular}{|c|c|c|c|c|c|}
\hline Index question & $\begin{array}{l}\text { No. of responses } \\
\text { made }\end{array}$ & Base question & $\begin{array}{l}\text { No. of expected } \\
\text { responses }\end{array}$ & $\begin{array}{l}\text { Completeness } \\
\text { of responses } \\
\text { (\%) }\end{array}$ & Comments \\
\hline $\begin{array}{l}\text { Where did you go to } \\
\text { get this done? }\end{array}$ & 174 & $\begin{array}{l}\text { NQ4: Did you have such a } \\
\text { pregnancy in the last } 5 \\
\text { years? (yes/no) }\end{array}$ & 174 & $\begin{array}{l}174 / 174= \\
100.0 \%\end{array}$ & $\begin{array}{l}\text { Response is count } \\
\text { of places they went }\end{array}$ \\
\hline $\begin{array}{l}\text { How much did you pay for } \\
\text { this abortion, including gifts } \\
\text { or money given to the } \\
\text { doctor (or person who } \\
\text { performed this abortion)? }\end{array}$ & 174 & $\begin{array}{l}\text { NQ4: Did you have such a } \\
\text { pregnancy in the last } 5 \text { years? } \\
\text { (yes/no) }\end{array}$ & 174 & $\begin{array}{l}174 / 174= \\
100.0 \%\end{array}$ & $\begin{array}{l}\text { Response is counts } \\
\text { of payments made }\end{array}$ \\
\hline
\end{tabular}

I think the perception the community has about abortion... how they stigmatise those who have done abortions... Sometimes you are seen as a murderer, so someone who has had an abortion would not like to open up (Interviewer, Kintampo, Ghana)

This could contribute to TOP being less reported as compared to miscarriages, which are perceived as natural. Younger females out of shyness and perceived stigma were also not willing to disclose TOP as per observations of interviewers.

There was a perception amongst interviewers and women that TOP reporting was not comfortable. Furthermore, unlike information on livebirths that is recorded in antenatal care records, documentation on TOP is hard to come by. Interviewers therefore could only depend on reports from persons who have experienced TOPs.

\section{Facilitators of TOP reporting}

Interviewers perceived good interviewer communication techniques to facilitate TOP reporting. These included speaking the same language (e.g. English or local) as the interviewees and the use of "softer" contextually appropriate expressions other than a direct reference to TOP.

What makes it easier for us is instead of asking the woman how many times she has had an abortion, you ask her how many times she has 'taken out her stomach' (Interviewer, Bandim, Guinea-Bissau)
With the diversity of reasons for engaging in TOP and its stigmatised nature, interviewers described needing to develop the tact of adapting to each interviewee's individual needs whilst not being judgmental. The informed consent process was viewed by interviewers as important in enhancing TOP disclosure by assuring respondents of confidentiality and that information gathered would be used to the benefit of the community.

It was observed by interviewers that when interviewees perceived they are speaking to a healthcare professional, they were much more open in disclosing TOP and other adverse pregnancy outcomes, potentially due to a level of trust for the health professional that might not be available for non-health professionals.

Interviewers observed that individual-level factors perceived to facilitate reporting by the women included personality of the respondent, with some outspoken persons much more likely to report TOP; when the woman felt justified in having a TOP, for example when conceiving immediately after a successful pregnancy; or conversely when a woman regretted an event after she was left with no children.

\section{Discussion}

Measuring TOP is methodologically challenging, and the structure and format of the interview itself is believed to be relevant in eliciting disclosure. Based on data from five countries and 34,371 women of reproductive age, we found that responses to the new questions on TOP were high and facilitated TOP disclosure from women

Table 3 Percent of women reporting lifetime events ${ }^{a}$ in roster, new Menstrual Restoration, and TOP questions of EN-INDEPTH Survey

\begin{tabular}{llll}
\hline Site & Roster TOP question & New menstrual restoration questions & New TOP questions \\
\hline Percent (95\% confidence interval [CI]) & & - \\
Bandim & $6.7(5.5-8.2)$ & - & $2.0(1.0-3.4)$ \\
Dabat & $1.2(0.3-2.9)$ & $6.0(4.7-7.6)$ & - \\
IgangaMayuge & $6.0(4.8-7.5)$ & $17.2(15.4-19.0)$ & $11.5(8.8-14.7)$ \\
Kintampo & $13.2(11.4-15.2)$ & $12.0(9.9-14.40)$ & $15.5(13.9-17.3)$ \\
Matlab & $14.0(12.4-15.7)$ & - & \\
\hline
\end{tabular}

${ }^{\mathrm{a}}$ Events are TOP, restoration of menstruation and TOP, respectively 


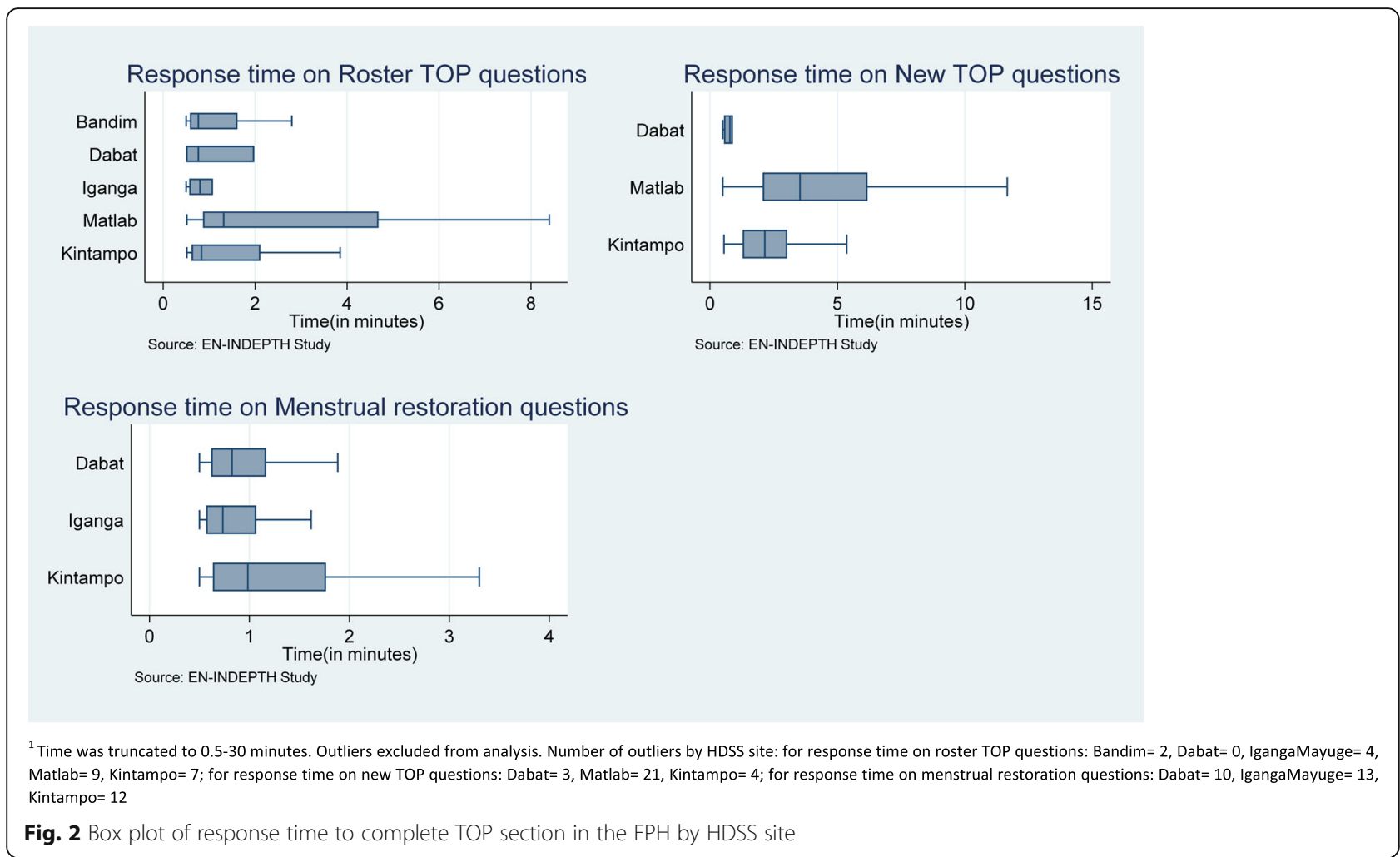

who had not reported them with the roster questions. The new questions could therefore help improve TOP measurement. Termination of pregnancy was perceived as stigmatising, and uncomfortable to disclose, being particularly shameful amongst young women. As such, survey teams should prepare the members to eschew judgmental and stigmatising behaviours and be accommodating of interviewees' specific circumstances.

Completeness of responses to roster TOP questions, and new Menstrual Restoration and TOP questions were generally high, implying that respondents understood them. A key observation was that once women acknowledged a TOP or delayed menstruation, they reported on most of the other questions related to that event.

With the exception of Guinea-Bissau where no prior rates were identified, significant differences were observed between TOP rates reported in the current study and those from previous studies in countries representing the other study sites [12, 24-27]. These differences could be attributed to TOP characteristics at study sites varying from those in the respective countries overall, methodological differences in data collection, and adjustment factors applied. Also, consistent with prior studies $[14,34]$, the population TOP rates were underestimated by the roster TOP questions considering the additional responses to the new questions on TOP. The roster TOP questions elicited slightly higher TOP rates in Kintampo, Ghana, when compared to the new questions on
TOP, with the reverse happening in Matlab,Bangladesh. Dabat, Ethiopia, had low TOP rates for both the roster and new questions on TOP. Except for the place where they were carried out, respondents who had Menstrual Restoration completely disclosed the processes they went through. Menstrual Restoration rates in Kintampo, Ghana, were similar to TOP rates from the roster TOP and new TOP questions. Menstrual Restoration rates in IgangaMayuge, Uganda, were relatively lower than TOP rates from the roster TOP questions. Differences in the observed rates across sites could be due to cultural variations in how respondents relate to TOPs and their perception of Menstrual Restoration.

Shi and colleagues describe the relevance of response times in determining the characteristics of questions used in surveys, their influence on interviewee's comprehension, and interviewer performance [31]. Our findings show that average response time for completing the roster TOP questions varied across the five HDSS sites. Comparing these sites, the median response time was highest in Matlab, Bangladesh, and least in Bandim, Guinea-Bissau. Mean time was highest in Matlab, Bangladesh, and lowest in Dabat, Ethiopia. Similarly, mean time spent in answering the new TOP questions was highest in Matlab, Bangladesh, and lowest in Dabat, Ethiopia. No previous populationbased studies were found with response times on a similar set of TOP questions, and whilst longer response times may be associated with more considered responses, 
Table 4 Perceptions, practices, barriers, and facilitators to reporting termination of pregnancy in five EN-INDEPTH study sites

\begin{tabular}{|c|c|}
\hline & Woman \\
\hline \multicolumn{2}{|c|}{ Perceptions on reporting TOPs } \\
\hline $\begin{array}{l}\text { TOPs immoral } \\
\text { and inhuman }\end{array}$ & $\begin{array}{l}\text { - Enquiring of a bad event is perceived unethical } \\
\text { (Dabat, Ethiopia) }\end{array}$ \\
\hline & $\begin{array}{l}\text { - TOP perceived as taking a life } \\
\text { Why did you abort the baby? Why did you kill a life? } \\
\text { What would have been the problem if you had that } \\
\text { child? Can't you rear it up? If you think you cannot } \\
\text { take care of it then you have [to] give it to someone } \\
\text { for adoption! But why did you abort the baby? } \\
\text { (Iganga-Mayuge, Uganda) }\end{array}$ \\
\hline
\end{tabular}

\section{Perceived TOP reporting practices}

Difficulty reporting TOPs - It is one's secret and shameful to tell others That one (abortion) is a secret so you won't disclose it to people apart from telling your trusted friend. Maybe you didn't know what to do and it was that friend who advised you on how to carry out the abortion. So, if you tell someone about it, the day the two of you will have arguments, the person will use it to insult you. It is shameful to tell people that you have aborted a pregnancy, so it is not possible to easily disclose it (Kintampo, Ghana)

- Pain of loss perceived to be self-afflicted, so one cannot openly grieve

In that case (TOP) there is no grievance. If she actually felt bad, then does she ever do such thing?... If I have to do that unwillingly, I will have to bear more sorrow (Matlab, Bangladesh) Interviewer

- Culture and religion consider TOP as immoral and inhuman

Also, in the Christian community, abortion is seen to be a bad thing, so it is very difficult to get responses to questions on abortion (Kintampo, Ghana)

- It is much more comfortable reporting livebirths. If you ask the woman she does not want to talk about abortion, she only wants to talk about those children that she gave birth to (Bandim, Guinea-Bissau)

- Interviewers not being empathetic and patient Sensitive questions must be asked systematically and with care so as not to remind the women of their loss. Being empathetic and patient with her can yield the right information. The problem is most data collectors are in a hurry and not conscious of the women's grief, so they to ask directly about this sensitive issue. Consequently, the interview ends up with the wrong information (Dabat, Ethiopia)

- Young girls generally shy away from reporting TOPs Then the other thing on the part of the girls, most of them were not open to disclose information about pregnancies. Some of them were shying away from telling us that they aborted... (Iganga-Mayuge, Uganda)

- TOPs reported as miscarriages instead We are realizing this challenge of abortion that some women can't tell you that this abortion was intended. This is a big problem to me. She can't tell you that this was a miscarriage but when you reach here, she says no, so they hide the information. She says it was a miscarriage, but she fears to tell you that this was intended abortion (Iganga-Mayuge, Uganda)

\section{Perceived barriers to reporting TOPs}

Interviewer unable to ask TOP questions or

- It is a taboo to ask a woman about TOP If there is an abortion or other adverse events, perceived as disrespectful another pregnancy will come soon as the woman is not lactating. Enquiring about such adverse events is really miserable, perceived as a taboo and as wanting to harm the woman (Dabat, Ethiopia)
Stigma associated with TOPs

\footnotetext{
- TOPs are perceived to be linked to heredity and fear reoccurrence of the problem in the next pregnancy (Dabat, Ethiopia)
}

- Interviewers who probe on TOP are perceived as disrespectful

The difficulty is when you ask a woman something, and she says, "is this what you are asking me, my son?" I say, "No auntie, ok, ok, we just want to know how many children, it is not like this, but we want to know how many abortions you have had". If you don't ask her in this way, the person becomes awkward and thinks you lack respect (lebsimente) because you seem keen to know about their life (Bandim, Guinea-Bissau)

- Interviewer's fear to ask direct questions on TOP due to legal and religious reasons

There is a challenge though somehow not that serious that relates to issues of legal and religion... we hear that abortion is illegal and when it comes to the question that asks direct that "did you do anything to end this pregnancy?" this it requires you to be trained and less judgmental (lganga-Mayuge, Uganda)

- Younger females not willing to disclose TOPs Some of them were shying away from telling us that they aborted (Iganga-Mauyge, Uganda) 
Table 4 Perceptions, practices, barriers, and facilitators to reporting termination of pregnancy in five EN-INDEPTH study sites (Continued)

\begin{tabular}{l} 
Woman \\
\hline Ceporting TOPs \\
$\begin{array}{l}\text { Very uncomfortable } \\
\text { repots of women did not want to think } \\
\text { about, more so talk about TOPs } \\
\text { God gave and God took it! (Dabat, } \\
\text { Ethiopia) }\end{array}$
\end{tabular}

Poor documentation of TOPs

\section{Interviewer}

- Persons who have done TOPs are stigmatised and perceived as murderers.

I think the perception the community has about abortion...how they stigmatize those who have done abortions... Sometimes you are seen as a murderer, so someone who has had an abortion would not like to open up (Kintampo, Ghana)

- Miscarriages easier reporting than TOPs as they are perceived as natural

For me personally getting information on miscarriages is not as difficult as that of abortion because they see the miscarriage as a natural occurrence (Kintampo, Ghana)

- Some women are just uncomfortable disclosing TOPS Some of them feel very uncomfortable giving you such details and also some of them find it difficult in giving you details about children that they have lost depending on the circumstance under which they lost the child (Kintampo, Ghana)

- There are rarely records of TOPs as compared to livebirths, etc. so information solely depends on what the woman provides

There is a bit of records to get on the neonatal births and livebirths as compared to miscarriages and abortion. It also depends solely on the woman to give you all the details of since there are no records on it in the ANC so it all boils down to the kind of rapport and relationship you build with her (Kintampo, Ghana)

\section{Perceived facilitators of TOP reporting}

Good interviewer

techniques

A common language

of interaction

Informed consent

process is well done
- Making use of "expressions" that tacitly inquire about TOPs in place of explicit language

What makes it easier for us is instead of asking the woman how many times she has had an abortion; you ask her how many times she has 'taken out her stomach' (Bandim, Guinea-Bissau)

- Communicating with the husband or her mother is one way of getting reliable information (Dabat, Ethiopia)

- Or speaking to the woman after she recovers from her grief may be another alternative.

Interviewer must be able to gauge the right moment to ask questions

You have to also be careful not to directly go to the questionnaire. You must first get her attention and concentration by understanding her feelings, facial expressions, and readiness to share the information (Dabat, Ethiopia)

- TOPs are stigmatised and reasons for carrying them out are diverse, so interviewer's craftiness facilitates disclosure With the abortions, we have made it look like something that is really bad and scary. If someone has committed abortion, she is even afraid of saying it because she thinks she will be reported for the society to have a certain perception about her. There are different reasons why someone will have an abortion, some young girls are afraid of their parents so when they get pregnant, they will rather choose to abort it, some are also based on doctors' advice. So, you have to be really careful when asking on the field (Kintampo, Ghana)

- Speaking the language of the interviewee enhance disclosure Apart from this consenting issue, sometimes the language also helps, especially when you speak their language (Kintampo, Ghana)

- Providing detailed and enough information during the consenting process facilitates disclosure.

A good consenting process assures respondents of the use of 
Table 4 Perceptions, practices, barriers, and facilitators to reporting termination of pregnancy in five EN-INDEPTH study sites (Continued)

\begin{tabular}{|c|c|c|}
\hline & Woman & Interviewer \\
\hline & & $\begin{array}{l}\text { information gathered to improve their and other's outcomes. } \\
\text { Sometimes when the respondent has many of such incidence } \\
\text { (TOP), when you consent her very well, she will have the mindset } \\
\text { that the Ghana Health Service will implement policies that will } \\
\text { help to reduce these things and they are willing to give you } \\
\text { information (Kintampo, Ghana) }\end{array}$ \\
\hline $\begin{array}{l}\text { Feeling justified or } \\
\text { open-minded on TOP }\end{array}$ & $\begin{array}{l}\text { - Women are much more open when } \\
\text { speaking about miscarriages, though } \\
\text { still they hide some information. } \\
\text { Abortions or miscarriages are perceived } \\
\text { to be related to hereditary or } \\
\text { uterine problems (Dabat, Ethiopia) }\end{array}$ & $\begin{array}{l}\text { - Some interviewees disclose TOPs as they feel justified in the } \\
\text { reasons for doing it } \\
\text { I found a woman and when I asked that "have you ever had a } \\
\text { miscarriage?" she said that "not even miscarriage but I just } \\
\text { aborted" and that the reason was that the rate of conception } \\
\text { was high because when the child was only } 3 \text { months she could } \\
\text { conceive and when she tried family planning she said that "it } \\
\text { was like I had loosen the tap because the bleeding was too } \\
\text { much" (Iganga-Mayuge, Uganda) }\end{array}$ \\
\hline & & $\begin{array}{l}\text { - Some interviewees do not hide their experiences with TOP, } \\
\text { they speak openly } \\
\text { I will say it is the personality, some people are outspoken, they } \\
\text { are able to tell what they have gone through, sometimes I } \\
\text { myself I get surprised when the women tell me that I aborted } \\
\text { this pregnancy despite the difficulty in saying it, sometimes } \\
\text { some people come out clear on that (Kintampo, Ghana) }\end{array}$ \\
\hline $\begin{array}{l}\text { A sense of regret } \\
\text { over TOP }\end{array}$ & $\begin{array}{l}\text { - Some disclose due to guilt they feel } \\
\text { over their actions } \\
\text { They talk about it because... I have ever } \\
\text { seen a woman who aborted and buried } \\
\text { the fetus in the anthill. So, she spoilt her } \\
\text { future because over time... she wanted } \\
\text { to give birth to a child but in vain } \\
\text { (Iganga-Mayuge, Uganda) }\end{array}$ & \\
\hline $\begin{array}{l}\text { Perception of speaking } \\
\text { to a healthcare provider }\end{array}$ & & $\begin{array}{l}\text { - Interviewees feel secure speaking to interviewers they perceive } \\
\text { to be health workers } \\
\text { Like the technique of her seeing you in the perspective of "musawo", } \\
\text { [doctor] so she does not want to deceive you, ahaa me, musawo } \\
\text { the other husband, we separated, with my husband and that's } \\
\text { why I aborted these pregnancies but don't let him know and the } \\
\text { police will accuse me of this illegal abortions and for you accept } \\
\text { to be called musawo but again when you say you are not a } \\
\text { nurse, she will ask you why you have been asking her about } \\
\text { that and she will say I have been talking with a wrong person } \\
\text { (lgangaMayuge, Uganda) }\end{array}$ \\
\hline
\end{tabular}

implementing questions with long response times in a standard DHS survey is unlikely to be feasible.

Respondents in the current study brought to light certain community perceptions and practices that influence TOP reporting. Cultural and religious perceptions of TOP as inhuman and immoral influenced its reporting. Associated societal stigma, moral condemnation, and shaming observed in Cameroon, Kenya, and elsewhere [3, 35-37] resulted in women keeping TOP secret. Perceived stigma led to some women in the current study reporting TOP as miscarriage or not report it altogether [21]. Judgmental attitudes like tagging persons with TOP as taking a life, not having a heart, etc. adversely influenced reporting [21, 37]. Women in a Cameroonian study perceived TOP as immoral and criminal but went ahead for socio-economic reasons [35].
Some perceived barriers to reporting TOP emerged in the current study. Perceived and internalised stigma influence reporting or openly discussing TOP [21, 26, 38]. Fear of adverse reactions like harassment and rejection from partners, parents, etc. made women apprehensive of sharing information of intended TOP, whereas others related it to close friends or siblings who ever had abortions [21, 36-39]. These findings are consistent with previous studies where perceptions of TOP as evil, abnormal, only carried out by commercial sex-workers or murder fuelled feelings of stigma in women [21, 36, 40, 41]. Younger women were much more likely to perceive judgement by others or selfjudgement and associated complications of perceived stigma [42], making them less likely to report TOP as in the current study. Huntington and colleagues observed that judgmental or stigmatising attitudes adversely influenced 
TOP reporting than fear of legal or moral implications [43]. Interviewers in the current study on the contrary wanted to avoid TOP questions apprehensive of legal and religious implications. Survey teams therefore require a deep appreciation of cultural, religious, and other contextual factors that influence TOP reporting inculcated into training of members to enhance their competence at appropriately interacting with study participants.

Perceived facilitators of TOP reporting as per the current study were good interviewer skills such as knowledge of contextually appropriate TOP expressions, adapting to each woman's individual needs and using a common language, similar to findings of a Cameroonian study [35]. Interviewers' influence on TOP reporting as per a Malawian study cannot be underestimated [20]. Interviewer gender was not perceived as a facilitator for TOP reporting in the current study in contrast with others from Mexico and some African countries [44, 45]. In our study, some women reported TOP out of feelings of regret and justification of their actions. Individuals' feelings post-TOP varies-studies have reported school-going females and commercial sexworkers were frequently relieved $[37,46]$ whilst others with outcomes like infertility and trauma may experience religious and legal guilt coupled with jealousy [46]. Adolescents are more willing to discuss their peers' experience of TOP than their own [18].

Interviewee trust in healthcare professionals and wellperformed informed consent procedures were perceived to enhance TOP reporting in the current study. Consenting for the roster and new questions on TOP were the same; hence, differences in responses could be attributed to the type of questions asked. Question framing and sequencing were perceived to facilitate TOP reporting in the current and Huntington and colleagues' studies [43], possibly contributing to the additional responses in the new questions on TOP. The roster TOP questions being direct in nature could have generated perceptions of guilt or judgement that made it difficult for respondents to report TOP. The new questions on TOP by their "soft" approach could have made the same respondents feel less judged-possibly resulting in extra TOP reporting.

\section{Implications of study findings on TOP measurement}

Potential next steps for improving direct TOP measurement in women's questionnaires in populationbased surveys premised on findings of this study include (1) enhanced pre-survey interviewer training sessions, to include training in TOP specific terminology used in the communities and training to address stigma and judgmental attitudes, and the need to accommodate interviewee's specific circumstances; and (2) improved survey processes, including attention to accurate translation of TOP specific questions and interviewer prompts to include commonly understood lay-terms and ensuring the informed consent process is appropriately executed, describing the benefits or otherwise of the study to participants and the wider society.

Specific implications for DHS and Multiple Indicator Cluster Surveys (MICS): The mean and median times for TOP interviews point to the fact that TOP questions would not overly burden respondents or the interview team. Some respondents with a past TOP did not report the event with the standard roster questions, but only with the additional new questions where an additional lead-in question "It is not uncommon for a woman to get pregnant at a time when circumstance would make it difficult to have a child. Have you ever gotten pregnant at a time when it would have been difficult for you to have a child, or when you did not want to have one?" was asked prior to the standard question on whether the woman successfully did anything to end that pregnancy. It is possible that this lead-in question may have made women feel more at ease in reporting these events, and the potential for including a similar question in the roster could be considered. A notable observation was that respondents who reported a pregnancy ending in a TOP or Menstrual Restoration went on to respond to further questions regarding that event.

\section{Strengths and limitations}

Strengths of the study include a large and diverse group of study participants from HDSS sites in five countries on the continents of Africa and Asia. A lot of effort went into developing standardised and uniform data collection tools that were tested ahead of the study; this ensured that data generated were comparable across the five study sites and made pooled analysis possible. The Survey Solutions software allowed the assessment of the time women spent in responding to TOP questions, which was a very important aspect of this study. The new questions on Menstrual Restoration and TOP exhibited their potential for eliciting information on women's management of delayed menstruation and extra TOP events, respectively. Perspectives on factors influencing TOP reporting were enriched by the views of survey interviewers and women who had first-hand experiences related to TOP reporting. We also note that varying legal, religious and cultural differences in the study contexts may have influenced TOP reporting differentially.

\section{Research gaps for improving measurement of TOP in household surveys}

It would be prudent to design and undertake experimental studies powered to ascertain the capacity of the new questions on TOP in eliciting information on TOP in comparison to other questions in populationbased surveys. Further exploration of paradata on response time could help determine the characteristics of TOP and menstrual restoration questions that influence interviewee and interviewer performances in such 
surveys. Except for Bangladesh, Menstrual Regulation/ Restoration is rarely reported from the other countries involved in this study; further studies exploring this phenomenon will bridge that knowledge gap.

\section{Conclusions}

All TOP question types were well responded to by the women. The roster TOP questions are likely to underrepresent the true population TOP rates. Findings from the current study support further exploration of the new questions using experimental designs in estimating TOP and Menstrual Restoration reporting. During preparations for future population-based surveys, cultural competencies of research teams should be enhanced and the need to adhere to appropriate informed consenting procedures should be emphasised to improve TOP reporting.

\section{Supplementary Information}

The online version contains supplementary material available at https://doi. org/10.1186/s12963-020-00238-9.

\section{Additional file 1: Details of qualitative methods (FGDs), EN-INDEPTH} study

Additional file 2: TOP rates per 1000 women 15-49 years over the five years preceding EN-INDEPTH survey from roster TOP questions.

Additional file 3: TOP ratio per 1000 livebirths over the five years preceding EN-INDEPTH survey from roster TOP questions.

Additional file 4: Table of EN-INDEPTH survey TOP questions.

Additional file 5: STROBE guidelines checklist.

Additional file 6: Table of socio-demographic characteristics of focus group discussion participants.

Additional file 7: Percentage of women with lifetime and five-year termination of pregnancies from FPH new questions on TOP (three HDSS sites).

Additional file 8: Time taken in minutes to complete TOP section by interviewers using paradata.

Additional file 9: Ethical approval of local Institutional Review Boards.

\section{Abbreviations}

DHS: Demographic and Health Survey; ENAP: Every Newborn Action Plan; EN-INDEPTH: Every Newborn-International Network for the Demographic Evaluation of Populations \& their Health; FBH+: Full Birth History (+ denotes additional questions on pregnancy losses); FGD(s): Focus group discussion(s); FIGO: International Federation of Gynaecology and Obstetrics; FPH: Full Pregnancy History; HDSS: Health and Demographic Surveillance System; HICs : High-income countries; LMICs: Low- and middle-income countries; MICS: Multiple Indicator Cluster Surveys; MNCH: Maternal, Newborn and Child Health; SDG: Sustainable Development Goals; TOP: Termination of pregnancy; UN: United Nations; WHO: World Health Organization

\section{Acknowledgements}

This supplement is dedicated to the memory of Professor Peter Byass, who was the Senior External Editor of the supplement. Peter died suddenly in August 2020 and will be greatly missed by the EN-INDEPTH study team and entire global health community.

We thank the 118 interviewers and many HDSS staff participating in this study for their hard work and dedication. Many thanks to Samuelina Arthur, Claudia DaSilva, Olivia Nakisita, Jacob Saah, Abdul-Karimu Alhassan, and all the site administrator staff for their administrative support. We acknowledge the core funders for all sites/institutions.
We express appreciation to the EN-INDEPTH expert advisory group: Fred Arnold, Peter Byass, Trevor Croft, Kobus Herbst, Sunita Kishor, Florina Serbanescu, Stephane Helleringer, Turgay Unalan, Shane Khan, Attila Hancioglu. Finally, and most importantly, we thank the women participating in the ENINDEPTH study and their families, without whom this work would not have been possible.

The Every Newborn-INDEPTH Study Collaborative Group:

Senior External Supplement Editors: Peter Byass; Stephen M Tollman; Hagos Godefay

Technical Supplement Editors: Joy E. Lawn; Peter Waiswa; Hannah Blencowe

Managing Supplement Editors: Judith Yargawa; Joseph Akuze (data and statistics)

Other EN-INDEPTH Collaborative Group Members:

By team: Pl followed by other members in alphabetical order

Bandim: Ane B Fisker (PI); Justiniano SD Martins; Amabelia Rodrigues; Sanne M Thysen

Dabat: Gashaw Andargie Biks (PI); Solomon Mokonnen Abebe; Tadesse Awoke Ayele; Telake Azale Bisetegn; Tadess Guadu Delele; Kassahun Alemu Gelaye; Bisrat Misganaw Geremew; Lemma Derseh Gezie; Tesfahun Melese; Mezgebu Yitayal Mengistu; Adane Kebede Tesega; Temesgen Azemeraw Yitayew

IgangaMayuge: Simon Kasasa (PI); Edward Galiwango; Collins Gyezaho; Judith Kaija; Dan Kajungu; Tryphena Nareeba; Davis Natukwatsa; Valerie Tusubira

Kintampo: Yeetey AK Enuameh (PI); Kwaku P Asante; Francis Dzabeng; Seeba Amenga-Etego; Alexander A Manu; Grace Manu; Obed Ernest Nettey; Sam K Newton; Seth Owusu-Agyei; Charlotte Tawiah; Charles Zandoh

Matlab: Nurul Alam (PI); Nafisa Delwar; M Moinuddin Haider; Md. Ali Imam; Kaiser Mahmud

LSHTM/ Makerere School of Public Health: Angela Baschieri; Simon

Cousens; Vladimir Sergeevich Gordeev; Victoria Ponce Hardy; Doris Kwesiga; Kazuyo Machiyama

\section{About this supplement}

This article has been published as part of Population Health Metrics Volume 19 Supplement 1, 2021: Every Newborn-INDEPTH study: Improving the measurement of pregnancy outcomes in population-based surveys. The full contents of the supplement are available online at https://pophealthmetrics. biomedcentral.com/articles/supplements/volume-19-supplement-1.

\section{Authors' contributions}

The EN-INDEPTH study was conceptualised by JEL. All EN-INDEPTH collaborative group and site teams contributed to the design of the study protocol and undertook data collection. YAKE together with FD, HB, and JEL developed the detailed research questions and overall analysis plan for this paper. These were refined with inputs from the wider EN-INDEPTH study collaborative group including VSG at a multi-country workshop in Entebbe Uganda in February 2019. SMT, SMA, SK, MAI, CZ, WA, SAE, and SKN implemented the study at the sites. Quantitative data analysis was undertaken by YAKE and FD, and HB provided statistical oversight. Qualitative analysis was undertaken by $C T, D K$, and WA. The manuscript was drafted by YAKE, JC, FD, HB, and JEL, and KPA, SOA, and PW provided valuable insights. All authors reviewed and agreed on the final version of the manuscript.

\section{Funding}

The EN-INDEPTH study (including publication costs) was funded by the Children's Investment Fund Foundation (CIFF) by means of a grant to LSHTM (PI Joy E. Lawn), and a sub-award to the INDEPTH MNCH working group with technical leadership by Makerere School of Public Health (PI Peter Waiswa).

\section{Availability of data and materials}

Data sharing and transfer agreements were jointly developed and signed by all collaborating partners. The datasets generated during the current study are deposited online at https://doi.org/10.17037/DATA.00001556 with data access subject to approval by collaborating parties.

\section{Ethics approval and consent to participate}

The EN-INDEPTH study was granted ethical approval by the Institutional Review Boards in all operating countries, as well as, from Institutional Ethical Review Committee of the London School of Hygiene \& Tropical Medicine 
(Additional file 9). Respondents of every successful interview gave written consent/ascent after being informed of the objective, data use, procedure of the interview, risks and benefits of participating in the study, right to withdraw from interview anytime point of time and not responding to questions where she feels discomfort. The study ensures the respondent's privacy at data collection and confidentiality at data use.

\section{Consent for publication}

Not applicable.

\section{Competing interests}

The authors declare no competing interests.

\section{Author details}

${ }^{1}$ Kintampo Health Research Centre, Kintampo, Ghana. ${ }^{2}$ Dept of Epidemiology \& Biostatistics, Kwame Nkrumah University of Science \& Technology, Kumasi, Ghana. ${ }^{3}$ Maternal, Adolescent, Reproductive \& Child Health (MARCH) Centre, London Sch. of Hygiene \& Tropical Medicine, London, UK. ${ }^{4}$ Bandim Health Project, Bissau, Guinea-Bissau. ${ }^{5}$ Research Centre for Vitamins and Vaccines, Statens Serum Institut, Copenhagen, Denmark. ${ }^{6}$ Department of Clinical Research Open Patient data Explorative Network (OPEN), University of Southern Denmark, Odense, Denmark. ${ }^{7}$ Dabat Research Centre Health and Demographic Surveillance System, Dabat, Ethiopia. ${ }^{8}$ Department of Health Systems and Policy, Institute of Public Health, University of Gondar, Gondar, Ethiopia. ${ }^{9}$ The Institute of Population Health Sciences, Queen Mary University of London, London, UK. ${ }^{10}$ Department of Health Policy, Planning and Management, Makerere University School of Public Health, Kampala, Uganda. ${ }^{11}$ International Maternal \& Child Health, Department of Women and Children's Health, Uppsala University, Uppsala, Sweden. ${ }^{12}$ Centre of Excellence for Maternal Newborn and Child Health Research, Makerere University, Kampala, Uganda. ${ }^{13}$ IgangaMayuge Health and Demographic Surveillance System, Iganga, Uganda. ${ }^{14}$ Makerere University Centre for Health and Population Research, Makerere, Uganda. ${ }^{15}$ Department of Epidemiology \& Biostatistics, Makerere University School of Public Health, Kampala, Uganda. ${ }^{16}$ Health Systems and Population Studies Division, icddr,b, Dhaka, Bangladesh. ${ }^{17}$ Department of Global Health, Kwame Nkrumah University of Science \& Technology, Kumasi, Ghana. ${ }^{18}$ Institute of Health Research, University of Health and Allied Sciences, Ho, Ghana. ${ }^{19}$ Centre of Excellence for Maternal Newborn and Child Health Research, Makerere University, Kampala, Uganda. ${ }^{20}$ Department of Global Public Health, Karolinska Institutet, Stockholm, Sweden.

\section{Published: 8 February 2021}

\section{References}

1. Guttmacher Institute: Induced abortion worldwide - global incidence and trends. 2019. https://www.guttmacher.org/fact-sheet/induced-abortionworldwide [Accessed Aug 2019].

2. Sedgh G, Bearak J, Singh S, Bankole A, Popinchalk A, Ganatra B, Rossier C, Gerdts C, Tunçalp Ö, Johnson BR Jr. Abortion incidence between 1990 and 2014: global, regional, and subregional levels and trends. Lancet. 2016;388: 258-67.

3. Singh S, Remez L, Sedgh G, Kwok L, Onda T. Abortion worldwide 2017: uneven progress and unequal access; 2018.

4. Ganatra B, Gerdts C, Rossier C, Johnson BR Jr, Tunçalp Ö, Assifi A, Sedgh G, Singh S, Bankole A, Popinchalk A. Global, regional, and subregional classification of abortions by safety, 2010-14: estimates from a Bayesian hierarchical model. Lancet. 2017;390:2372-81.

5. Áhman $\mathrm{E}$, Shah $\mathrm{H}$. New estimates and trends regarding unsafe abortion mortality. Int J Gynecol Obstet. 2011;115:121-6.

6. Banerjee SK, Andersen KL, Buchanan RM, Warvadekar J. Woman-centered research on access to safe abortion services and implications for behavioral change communication interventions: a cross-sectional study of women in Bihar and Jharkhand, India. BMC Public Health. 2012;12:175.

7. Rossier C. Estimating induced abortion rates: a review. Stud Fam Plan. 2003; 34:87-102.

8. Salomonsen EL. Unsafe abortion in legally restricted areas. How politics and abortion laws decides women's future. A literature review on the incidence of induced abortion and adverse health consequences in Sub-Saharan African countries with restrictive abortion laws: UiT Norges arktiske universitet; 2017
9. Moreau C, Bajos N, Bouyer J. Question comprehension and recall: the reporting of induced abortions in quantitative surveys on the general population. Population. 2004:59:439-54.

10. Lindberg L, Kost K, Maddow-Zimet I, Desai S, Zolna M. Abortion reporting in the United States: an assessment of three national fertility surveys. Demography. 2020;57:899-925.

11. Ghana Statistical Service (GSS) GHSG, ICF. Ghana maternal health survey 2017. Ghana: Accra; 2018.

12. Keogh SC, Otupiri E, Chiu DW, Polis CB, Hussain R, Bell SO, Nakua EK, LarsenReindorf R. Estimating the incidence of abortion: a comparison of five approaches in Ghana. BMJ Glob Health. 2020;5:e002129.

13. Bell SO, Sheehy G, Hyacinthe AK, Guiella G, Moreau C. Induced abortion incidence and safety in Côte d'Ivoire. PloS one. 2020;15:e0232364.

14. Sedgh G, Keogh SC. Novel approaches to estimating abortion incidence. Reprod Health. 2019:16:44.

15. Baschieri A, Gordeev VS, Akuze J, Kwesiga D, Blencowe H, Cousens S, Waiswa P, Fisker AB, Thysen SM, Rodrigues A, et al. "Every Newborn-INDE PTH"(EN-INDEPTH) study protocol for a randomised comparison of household survey modules for measuring stillbirths and neonatal deaths in five Health and Demographic Surveillance sites. J Glob Health. 2019;9(1): 010901.

16. Sánchez-Páez DA, Ortega JA. Reported patterns of pregnancy termination from demographic and health surveys. PLoS One. 2019;14(8):e0221178.

17. Moscrop A. 'Miscarriage or abortion?'Understanding the medical language of pregnancy loss in Britain; a historical perspective. Med Human. 2013;39: 98-104.

18. Singh S, Remez L, Tartaglione A. Methodologies for estimating abortion incidence and abortion-related morbidity: a review. New York: Guttmacher Institute; 2010

19. MacQuarrie KLD, Winfrey W, Meijer-Irons J, Morse A. Consistency of reporting of terminated pregnancies in DHS calendars. In: DHS methodological reports. Rockville: ICF. p. 126.

20. Leone T, Sochas L, Coast E. Depends who's asking: interviewer effect on abortion data in sub-Saharan African demographic and health surveys (DHS). In: Population Association of America Annual Meeting; 10-13 April 2019: Austin, Texas; 2018

21. Shellenberg KM, Moore AM, Bankole A, Juarez F, Omideyi AK, Palomino N, Sathar $Z$, Singh S, Tsui AO. Social stigma and disclosure about induced abortion: results from an exploratory study. Global Public Health. 2011;6:S111-25.

22. von Elm E, Altman DG, Egger M, Pocock SJ, Gøtzsche PC, Vandenbroucke JP: Strengthening the reporting of observational studies in epidemiology (STROBE) statement: guidelines for reporting observational studies. BMJ. 2007:335:806.

23. Guttmacher Institute: Abortion in Africa. 2018. https://www.guttmacher.org/ sites/default/files/factsheet/ib_aww-africa_0.pdf [Accessed Jan 2020].

24. Singh S, Hossain A, Maddow-Zimet I, Vlassoff M, Bhuiyan HU, Ingerick M. The incidence of menstrual regulation procedures and abortion in Bangladesh, 2014. Int Perspect Sex Reprod Health. 2017;43(1):11.

25. Rana J, Sen KK, Sultana T, Hossain MB, Islam RM. Prevalence and determinants of menstrual regulation among ever-married women in Bangladesh: evidence from a national survey. Reprod Health. 2019;16:123.

26. Moore AM, Gebrehiwot Y, Fetters T, Wado YD, Bankole A, Singh S, Gebreselassie H, Getachew Y. The estimated incidence of induced abortion in Ethiopia, 2014: changes in the provision of services since 2008. Int Perspect Sex Reprod Health. 2016:42:111.

27. Prada E, Atuyambe LM, Blades NM, Bukenya JN, Orach CG, Bankole A. Incidence of induced abortion in Uganda, 2013: new estimates since 2003. PLoS One. 2016;11:e0165812.

28. Kwesiga D, Tawiah C, Imam A, Kebede A, Nareeba T, Enuameh YAK, Manu G, Beedle A, Fisker A, Waiswa P, et al. Barriers and enablers to reporting of pregnancy and adverse pregnancy outcomes in population-based surveys: EN-INDEPTH study. BMC Population Health Metrics. 2021;19 (Supplement 1).

29. World Bank. Survey solutions CAPI/CAWI platform: Release 5.26. 2017. http:// surveys.worldbank.org/capi [Accessed May 2020].

30. Akuze J, Blencowe H, Waiswa P, Baschieri A, Gordeev VS, Kwesiga D, Fisker AB, Thysen SM, Rodrigues A, Biks GA, et al. Randomised comparison of two household survey modules for measuring stillbirths and neonatal deaths in five countries: the Every Newborn-INDEPTH study. Lancet Glob Health. 2020;8: e555-66.

31. Shi Y, Feng J, Luo X. Improving surveys with paradata: analytic uses of response time. China Popul Dev Stud. 2018;2:204-23. 
32. StataCorp: Stata statistical software: release 15. 2017.

33. QSR International: NVivo qualitative data analysis software. 1999. https:// qsrinternational.com/nvivo/nvivo-products/ [Accessed Mar 2020].

34. Bearak JM, Popinchalk A, Sedgh G, Ganatra B, Moller A-B, Tunçalp Ö, Alkema L. Pregnancies, abortions, and pregnancy intentions: a protocol for modeling and reporting global, regional and country estimates. Reprod Health. 2019;16:36.

35. Schuster S. Abortion in the moral world of the Cameroon grassfields. Reprod Health Matters. 2005;13:130-8.

36. Ushie BA, Juma K, Kimemia G, Ouedraogo R, Bangha M, Mutua M. Community perception of abortion, women who abort and abortifacients in Kisumu and Nairobi counties, Kenya. PLoS One. 2019;14:e0226120.

37. Sorhaindo AM, Juárez-Ramírez C, Olavarrieta CD, Aldaz E, Mejia Pineros MC, Garcia S. Qualitative evidence on abortion stigma from Mexico City and five states in Mexico. Women Health. 2014;54:622-40.

38. Loi UR, Lindgren M, Faxelid E, Oguttu M, Klingberg-Allvin M. Decisionmaking preceding induced abortion: a qualitative study of women's experiences in Kisumu, Kenya. Reprod Health. 2018;15:166.

39. Kimport K, Foster K, Weitz TA. Social sources of women's emotional difficulty after abortion: lessons from women's abortion narratives. Perspect Sex Reprod Health. 2011:43:103-9.

40. Atere AA, Ayodele JO, Omololu O. Abortion and Challenges of Teenage Pregnancy in Lagos, Nigeria. Int I Sci Eng Res. 2012;4:10.

41. Cockrill K, Nack A. "I'm not that type of person": managing the stigma of having an abortion. Deviant Behav. 2013;34:973-90.

42. Makleff S, Labandera A, Chiribao F, Friedman J, Cardenas R, Sa E, Baum SE. Experience obtaining legal abortion in Uruguay: knowledge, attitudes, and stigma among abortion clients. BMC Womens Health. 2019;19:155.

43. Huntington D, Mensch B, Miller VC. Survey questions for the measurement of induced abortion. Stud Fam Plan. 1996;27:155-61.

44. Flores-Macias F, Lawson C. Effects of interviewer gender on survey responses: Findings from a household survey in Mexico. Int J Public Opin Res. 2008;20:100-10

45. Haber N, Robyn PJ, Hamadou S, Yama G, Hien H, Louvouezo D, Fink G. Surveyor gender modifies average survey responses: evidence from household surveys in four Sub-Saharan African Countries [pre-print]. arXiv: 1810019812018

46. Oye-Adeniran BA, Adewole IF, Umoh AV, Iwere N, Gbadegesin A. Induced abortion in Nigeria: findings from focus group discussion. Afr J Reprod Health. 2005;9:133-41.

\section{Publisher's Note}

Springer Nature remains neutral with regard to jurisdictional claims in published maps and institutional affiliations.

Ready to submit your research? Choose BMC and benefit from:

- fast, convenient online submission

- thorough peer review by experienced researchers in your field

- rapid publication on acceptance

- support for research data, including large and complex data types

- gold Open Access which fosters wider collaboration and increased citations

- maximum visibility for your research: over $100 \mathrm{M}$ website views per year

At $\mathrm{BMC}$, research is always in progress.

Learn more biomedcentral.com/submissions 